\title{
Ebola and the Limited Effectiveness of Travel Restrictions
}

\author{
Morenike Folayan, FWACS; Brandon Brown, PhD, MPH
}

The current Ebola virus disease (EVD) outbreak in West Africa is the worst epidemic of Ebola since the first case was officially reported in 1976. The "traveling" of the infection from Guinea and Liberia to other parts of West Africa, Europe, and America has caused anxiety and panic. To control exportation and importation of EVD, the World Health Organization recommends exit screening in Guinea, Liberia, and Sierra Leone for unexplained febrile illness consistent with potential Ebola infection. ${ }^{1}$ Where entry screening is required, management systems must be in place to care for travelers and suspected cases in compliance with International Health Regulations requirements. ${ }^{1}$ By November 17, 2014, over 50 countries around the world had issued travel restrictions to and from Ebola-affected countries. ${ }^{2}$ The Centers for Disease Control and Prevention also recommends that US citizens avoid nonessential travel to Guinea, Liberia, and Sierra Leone and take precautions when traveling to Mali. ${ }^{3}$

Index patients with EVD outside Africa have been healthy at the time of arrival into the subsequent country, illustrating the difficulties provided by the incubation period of Ebola infection. Most cases of EVD managed outside of West Africa were citizens flown to their home countries for EVD care. Three were nurses exposed to EVD while managing patients. Three others were West Africans flown to Germany for management.

The implications of travel restrictions are vast. Travel restrictions make it harder to tackle the disease because the movement of supplies, equipment, and humanitarian aid to affected areas becomes difficult. $\mathrm{Eba}^{4}$ highlighted the human rights violations resulting from efforts to contain the epidemic and the limited success achieved from such measures. Similar to HIV, the current call to issue travel restrictions and to quarantine health care workers who return to their home country from affected countries in West Africa is rooted in fear. Such actions interfere with the rights of affected individuals and propagate stigma with far-reaching implications. Where suspected travelers from West Africa have symptoms suggestive of Ebola infection and quarantine is applicable, isolation facilities must be optimal with physical, social, and psychological support provided for all those quarantined and quality personal protective equipment provided for health care providers. ${ }^{5}$ Effective personal protective equipment is a beneficial disaster management strategy for Ebola. Travel restrictions are not the solution to containing Ebola.

\section{About the Authors}

Faculty of Dentistry, Obafemi Awolowo University, Ile-Ife, Nigeria (Dr Folayan), and Program in Public Health, University of California Irvine, Irvine, California (Dr Brown).

Correspondence and reprint requests to Dr Brandon Brown, Program in Public Health, UC Irvine, 653 E. Peltason Drive, 2024 AIRB, Irvine, CA 92697 (brandojb@uci.edu).

Published online: January 20, 2015.

\section{REFERENCES}

1. Statement on the 3rd meeting of the IHR Emergency Committee regarding the 2014 Ebola outbreak in West Africa. World Health Organization website. http://www.who.int/mediacentre/news/ statements/2014/ebola-3rd-ihr-meeting/en/. Published October 23, 2014. Accessed December 4, 2014.

2. Additional travel bans increasingly restrict travel to and from Ebola affected countries. Pro-Link GLOBAL website. https://prolinkglobal.com/global-additional-travel-bans-increasingly-restricttravel-to-and-from-ebola-affected-countries/. Published November 17, 2014. Accessed December 4, 2014.

3. Travel Health Notices. Centers for Disease Control and Prevention website. http://wwwnc.cdc.gov/travel/notices. Accessed December 4, 2014.

4. Eba MP. Ebola and human rights in West Africa. Lancet. 2014;384(9960):2091-2093. doi: 10.1016/S0140-6736(14)61412-4

5. Edmond MB, Diekema DJ, Rerencevich N. Ebola virus disease and the need for new personal protection equipment. JAMA. 2014;312(23):2495-2496. doi:10.1001/jama.2014.15497 